\title{
THE PATTERN OF BACTERIAL PATHOGENS AND THEIR ANTIBIOTIC SUSCEPTIBILITY PROFILE FROM LOWER RESPIRATORY TRACT SPECIMENS IN A RURAL TERTIARY CARE CENTRE
}

\author{
Asha Mary Thomas ${ }^{1}$, Chithra Jayaprakash², Gopala Menon Radhakutty Amma ${ }^{3}$ \\ 1 Final Year MBBS Student, MOSC Medical College, Kolenchery, Kerala. \\ ${ }^{2}$ Associate Professor, Department of Microbiology, MOSC Medical College, Kolenchery, Kerala. \\ 3Professor \& HOD, Department of Microbiology, MOSC Medical College, Kolenchery, Kerala.
}

\begin{tabular}{l}
\hline ABSTRACT \\
\hline BACKGROUND \\
Lower Respiratory Tract Infections (LRTIs) is one of the leading infective health problems worldwide. The inappropriate use of \\
antibiotics for these infections has led to a dramatic increase in antibiotic resistance among the respiratory pathogens. The choice \\
of antibiotics for the treatment of LRTIs has become limited.
\end{tabular}

AIM

To isolate the bacterial pathogens from the lower respiratory tract specimens, identify them and elaborate their antibiotic susceptibility profile using disc diffusion method.

\section{METHODS}

During the study period, 54 respiratory samples (27 sputum and 27 endotracheal secretions) were processed by following standard methods. The bacterial isolates were identified by standard biochemical reactions and their susceptibility testing done by Kirby-Bauer disc diffusion method. The results were interpreted as per CLSI (Clinical and Laboratory Standards Institute) guidelines.

\section{RESULTS}

Out of the 54 samples processed, 31 yielded significant growth (57.4\%). Only gram-negative bacterial pathogens (37 isolates, $68.52 \%$ ) were obtained during the study. The most common bacterial pathogen isolated was Pseudomonas aeruginosa (32.43\%), Klebsiella pneumoniae (27.03\%) ranking second; $59.45 \%$ of the bacterial isolates were multidrug resistant. The overall susceptibility of the gram-negative isolates was highest for colistin $(94.11 \%)$ followed by tigecycline $(71.40 \%)$ and co-trimoxazole (64.70\%). 22 (59.46\%) bacterial isolates were multidrug resistant.

\section{CONCLUSION}

The study yielded only gram-negative bacterial isolates, susceptibility being highest for colistin. Regular determination of the type of bacterial pathogens and their antibiotic resistance trends must be followed in every institution to aid in better patient management by helping the clinician in the judicious use of antibiotics.

\section{KEYWORDS}

Bacterial Pathogens, Lower Respiratory Infections, Drug Resistance.

HOW TO CITE THIS ARTICLE: Thomas AM, Jayaprakash C, Amma GMR. The pattern of bacterial pathogens and their antibiotic susceptibility profile from lower respiratory tract specimens in a rural tertiary care centre. J. Evolution Med. Dent. Sci. 2016;5(40): 2470-2476, DOI: $10.14260 /$ jemds/2016/576

\section{INTRODUCTION}

Lower Respiratory Tract Infections (LRTIs) are one of the main infective causes of morbidity and mortality in the world.(1) LRTIs though common in the general population, occur most frequently among patients in Intensive Care Units (ICUs). The LRTIs include bronchitis, bronchiectasis, bronchiolitis, emphysema, lung abscess, pleural effusion and pneumonia. Each type of LRTI vary in the epidemiology, pathogenesis, clinical presentation, and outcome.(2) The factors that contribute to the rising incidence of LRTIs in hospitals include underlying lung diseases, diabetes mellitus, malignancy, immunosuppressant drugs, inappropriate

Financial or Other, Competing Interest: None.

Submission 05-04-2016, Peer Review 29-04-2016,

Acceptance 06-05-2016, Published 19-05-2016.

Corresponding Author:

Dr. Chithra Jayaprakash,

Associate Professor

Department of Microbiology,

MOSC Medical College, Kolenchery,

Ernakulam-682311, Kerala.

E-mail: chithrasc@yahoo.com

DOI: $10.14260 /$ jemds $/ 2016 / 576$ antibiotic therapeutic.(3) Microscopic examination and culture of respiratory specimens remain the main stay of laboratory diagnosis of LRTIs. But procurement of good quality specimens is essential for the accurate reporting of results.

Many studies have observed that the majority of the respiratory bacterial pathogens are Gram negative. $(4,5,6)$ The aetiological agents of LRTIs and their antibiotic susceptibility profile vary from area to area. Streptococcus pneumoniae, Haemophilus influenzae, Klebsiella pneumoniae, Escherichia coli, Pseudomonas species, Acinetobacter species and other Non-Fermentative Gram-Negative Bacilli (NFGNB) have often been recovered from LRTIs. $(7,8)$

The most common bacterial pathogens isolated from LRTIs in some studies were Klebsiella pneumoniae $(K$. pneumoniae) and Pseudomonas aeruginosa ( $P$. aeruginosa).(6,9) But in the study by Navaneeth et al(5) nonfermentative gram-negative bacilli were the most common Gram-negative bacteria followed by Klebsiella species. Hospitalised patients become colonized rapidly with Gramnegative bacilli and it is often impossible to determine their clinical significance.

Bacterial pathogens isolated from tracheal aspirates tend to be more resistant to antibiotics than those from 
sputum isolates.(5) probably due to the higher antibiotic usage in the Intensive Care Units (ICUs). Two of the five risk factors for the emergence of multidrug resistance included antibiotic therapy administered within the preceding 90 days and the length of ICU stay.(10) Increasing antibiotic resistance among the respiratory tract pathogens has complicated the choice of antimicrobial agents.(11) Patients with risk factors often have a propensity to develop infections by Multidrug Resistant (MDR) organisms like Pseudomonas aeruginosa, Methicillin resistant Staphylococcus aureus (MRSA), Acinetobacter species and MDR Enterobacteriaceae. Another major contributor of resistance is the inappropriate empiric antibiotic therapy for LRTIs.(12) Failure to de-escalate the therapy after getting the culture and sensitivity report is another important reason for the drug resistance. Due to the inappropriate use of broadspectrum antibiotics like the third generation cephalosporins and carbapenems, antibiotics such as tigecycline and colistin have remained the only therapeutic options for LRTIs most of the time, although resistance to these drugs also have been recorded.(13) Hence, this study was conducted to investigate the bacterial aetiology of LRTIs and also to update the clinicians on the current antibiotic susceptibility pattern of these bacterial pathogens in this tertiary care centre in a rural area.

\section{MATERIALS AND METHODS}

\section{This is a Hospital Based, Cross-Sectional Study}

\section{i. Study Sample}

Lower respiratory specimens (sputum samples and endotracheal secretions) from patients with lower respiratory tract infections reaching the Microbiology Department of this tertiary care centre.

\section{ii. Study Area}

Microbiology Department of this Medical College.

iii. Study Permission

Permission to conduct the study obtained from the Medical Superintendent of this Medical College. Approval received from the Institutional Review Board and Ethics Committee.

iv. Study Design

Cross-sectional study.

v. Study Duration

2 months.

vi. Study Period

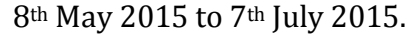

vii. Sample Size

54 (Measured using nMaster Sample Size computer software produced by The Department of Biostatistics, CMC Vellore, Tamil Nadu, India).

The sample size was calculated using the formula:

\section{viii. Sampling}

Serial recruitment of all respiratory samples reaching the Microbiology Department. Samples included in the study were sputum and Endotracheal Secretions (ETS).

\section{ix. Selection Criteria}

\section{Inclusion Criteria}

The sputum samples were graded by Bartlett's grading system.(14) Only those samples for which the score is $>0$ were included in the study. Endotracheal secretions with squamous cells less than $10 /$ low power field were included.

\section{Procedure of Isolation of Organisms}

Sputum samples and endotracheal secretions that reached the Microbiology lab of this institution were selected for the study. Quality of the sputum samples were assessed by visual inspection and from the relative numbers of squamous epithelial cells and neutrophils in direct Gram stain of the samples using Bartlett's grading system. Endotracheal secretions with more than 10 squamous epithelial cells per low power field were not included in the study. Samples showing less than 10 squamous epithelial cells per low power field were considered satisfactory, irrespective of the number of neutrophils. The samples were processed as soon as possible after collection. Sputum samples were vortexed for 1 minute and the undiluted samples inoculated on the culture medium using a Nichrome wire loop. Endotracheal secretions were vortexed for 1 minute, centrifuged at $3000 \mathrm{rpm}$ for 10 minutes and semi-quantitative culture was performed by the calibrated loop method using a wire loop of capacity 0.001 $\mathrm{mL}$. The culture media used for inoculation were blood agar, chocolate agar and MacConkey agar. The inoculated plates were incubated at $37^{\circ} \mathrm{C}$ for $18-24$ hours. The bacterial growth obtained from sputum samples were recorded as either No growth/Normal pharyngeal flora/Predominant growth. For endotracheal secretions, the bacterial colonies were counted. Colony counts of $\geq 10^{5} / \mathrm{mL}$ suggest potential pathogen. Identification of the isolates was done by standard microbiological procedures such as study of colony morphology, Gram stain reactions and a battery of standard biochemical tests. Antibiotic susceptibility testing was performed by Kirby-Bauer disc diffusion method on MuellerHinton agar. After incubation at $37^{\circ} \mathrm{C}$ for $18-24$ hours, the results were read and interpreted as per CLSI guidelines (Flow diagram shown).

\section{Study Definition}

Multidrug Resistance (MDR) is defined as resistance to more than 1 agent from 3 or more antimicrobial classes.(15)

\section{Ethical Issues}

Waiver of informed consent obtained. All data were assured to be stored anonymously and would be handled only by the investigator and authorized personnel.

\section{Statistical Analysis}

The data were analysed using Excel Spreadsheet and SPSS version 16 software. The frequency distribution of the organisms was tabled and summarized in a chart. The antibiotic susceptibility pattern was found out and the results were summarized in tables and charts.

\section{RESULTS}

During the period of study, a total of 54 consecutive samples (27 sputum samples and 27 endotracheal secretions), which fulfilled the inclusion criteria were accepted. Of the patients whose samples were accepted for the study, 40 (74\%) were males and 14 (25.9\%) females showing a male predilection. The age of the patients spanned from 14 to 84 years, the mean age being 54.06 years. Majority of the accepted samples were from inpatients $(94.4 \%)$ and only $5.6 \%$ from outpatients (OP); 44 patients $(81.48 \%)$ were known to have received at least one antibiotic prior to the collection of sample. 
Predominant growth/significant growth of bacterial isolates were recovered from 13 sputum (48.15\%) and 18 ETS $(66.67 \%)$ samples respectively. A total of 6 samples (11.11\%) yielded more than one bacterial isolate; 8 (14.81\%) samples did not yield any growth and no significant growth/normal pharyngeal flora was obtained in 13 (24.07\%) samples. Fungal growth was obtained from 2 (7.4\%) sputum samples (Table 1).

Only gram-negative bacteria (37 isolates, $68.52 \%$ ) were recovered from the 31 samples that yielded significant growth. These included members of the family Enterobacteriaceae (14 isolates, 37.84\%), Non-fermentative gram-negative bacilli (NFGNB-22 isolates, 59.45\%) and Moraxella catarrhalis (1 isolate, 2.7\%). The former included Klebsiella pneumoniae (27.03\%), Enterobacter species (5.4\%), Escherichia coli (2.7\%) and Serratia marcescens (2.7\%). The NFGNB isolated were Pseudomonas aeruginosa (32.43\%), Acinetobacter species (21.62\%), and NFGNB other than $P$. aeruginosa and Acinetobacter species (5.4\%). The most common bacterial isolate was $P$. aeruginosa $(32.43 \%)$ followed by $K$. pneumoniae (27.03\%) and Acinetobacter species (21.62\%) (Table 2). The distribution of these isolates among wards and ICUs is given in Table 3. P. aeruginosa (72.72\%) and Acinetobacter spp. (100\%) were the commonest respiratory pathogens in the ICUs.

The bacteria belonging to the family Enterobacteriaceae were more susceptible to antibiotics such as colistin
(92.86\%), tigecycline (71.42\%), carbapenems (71.43\%) and cotrimoxazole (64.29\%). They were least susceptible to ampicillin (0\%) and cephalexin (0\%) (Table 4). $K$ pneumoniae isolates were highly susceptible to colistin (90\%) and showed $60 \%$ susceptibility to tigecycline and carbapenems each (Table 5). The single isolate of E. coli was susceptible to colistin, tigecycline, carbapenems, cotrimoxazole and piperacillin/tazobactam. S. marcescens (1 isolate) was susceptible to all the antibiotics tested except ampicillin and cephalexin. The NFGNB in general were highly susceptible only to colistin (95\%). Pseudomonas aeruginosa the most common bacterial isolate in our study was most susceptible to colistin (91.66\%), amikacin (75\%) and gentamicin (75\%). They showed $50 \%$ susceptibility to imipenem and meropenem each. The Acinetobacter species in our study were isolated from endotracheal secretions. All were susceptible to colistin (100\%) and 2 isolates $(25 \%)$ were susceptible to amikacin and cotrimoxazole each. (Table $6)$.

$22(59.46 \%)$ bacterial isolates were multidrug resistant. They included $K$. pneumoniae (8 isolates, 36.36\%), Acinetobacter spp. (8 isolates, 36.36\%), P. aeruginosa (4 isolates, $18.18 \%$ ), E. coli (1 isolate, 100\%) and NFGNB other than $P$. aeruginosa and Acinetobacter spp. (1 isolate, 50\%) (Table 7). These MDR pathogens were isolated from 19 patients, of whom 17 received prior antibiotic treatment.

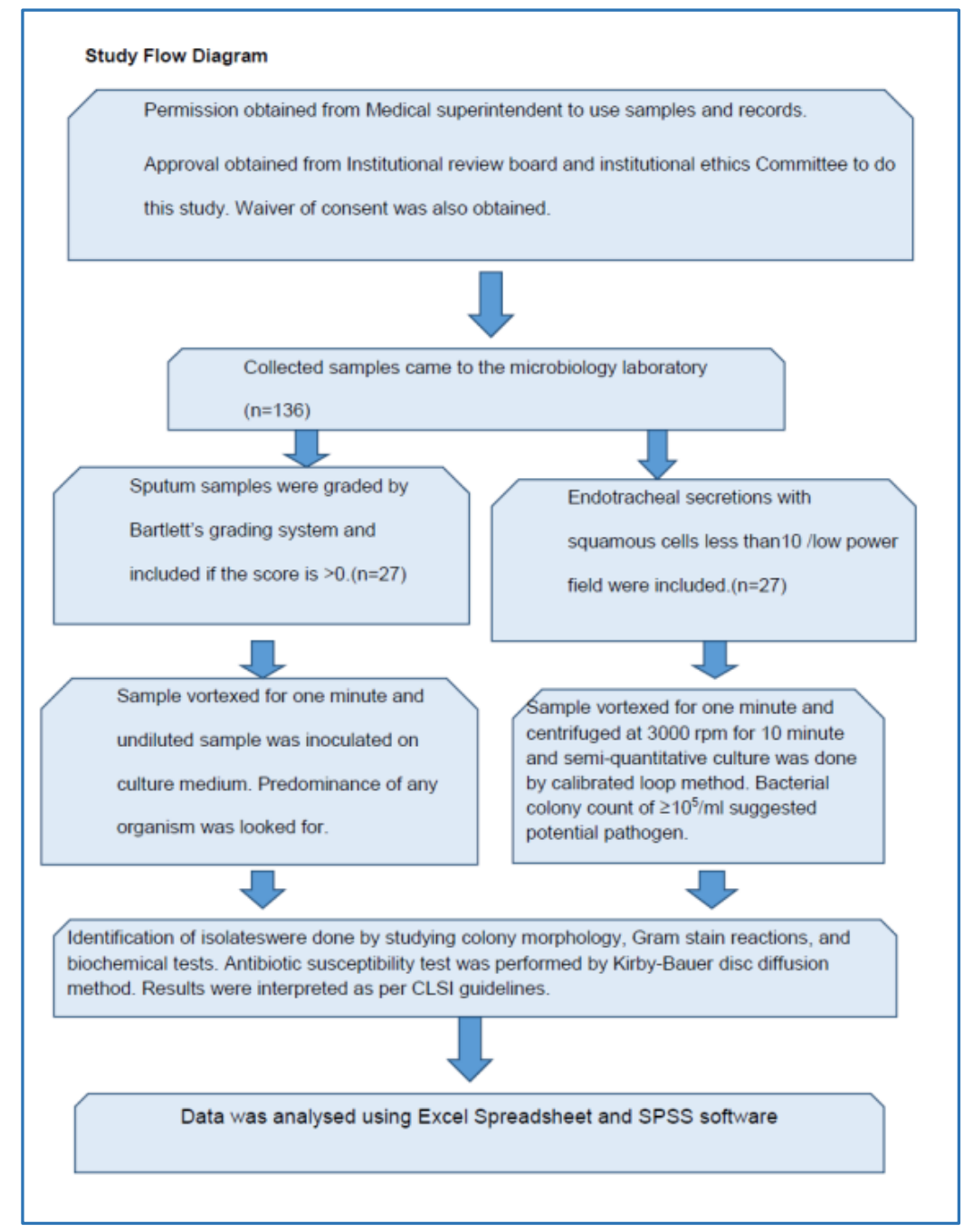




\begin{tabular}{|c|c|c|c|c|}
\hline & Ward & ICU & OP & Total \\
\hline \multirow{2}{*}{ No. of samples accepted } & $\begin{array}{c}15 \\
(27.77 \%)\end{array}$ & $36(66.66 \%)$ & $3(5.55 \%)$ & $54(100 \%)$ \\
\hline Sputum & $15(100 \%)$ & $9(25 \%)$ & $3(100 \%)$ & $27(50 \%)$ \\
\hline Endotracheal secretion & 0 & $27(75 \%)$ & 0 & $27(50 \%)$ \\
\hline Male & $10(66.66 \%)$ & $29(80.55 \%)$ & $1(33.33 \%)$ & $40(74 \%)$ \\
\hline Female & $5(33.33 \%)$ & $7(19.44 \%)$ & $2(66.66 \%)$ & $14(25.9 \%)$ \\
\hline Previous Antibiotic therapy & $11(73.33 \%)$ & $33(91.66 \%)$ & 0 & $44(81.48 \%)$ \\
\hline No growth & $1(6.66 \%)$ & $7(19.44 \%)$ & 0 & $8(14.81 \%)$ \\
\hline No significant growth & $5(33.33 \%)$ & $6(16.66 \%)$ & $2(66.66 \%)$ & $13(24.07 \%)$ \\
\hline Significant growth & $9(60 \%)$ & $21(58.33 \%)$ & $1(33.33 \%)$ & $31(57.4 \%)$ \\
\hline Polymicrobial growth & 0 & $6(16.66 \%)$ & 0 & $6(11.11 \%)$ \\
\hline Fungal growth & 0 & $2(5.55 \%)$ & 0 & $2(3.7 \%)$ \\
\hline
\end{tabular}

\begin{tabular}{|c|c|c|c|}
\hline \multicolumn{2}{|r|}{ Bacterial Isolate } & \multirow{2}{*}{$\frac{\text { No. }}{12}$} & \multirow{2}{*}{$\begin{array}{c}\% \\
32.43 \\
\end{array}$} \\
\hline 1) & Pseudomonas aeruginosa & & \\
\hline 2) & Klebsiella pneumoniae & 10 & 27.03 \\
\hline 3) & Acinetobacter spp. & 8 & 21.62 \\
\hline 4) & Enterobacter spp. & 2 & 5.4 \\
\hline 5) & $\begin{array}{l}\text { NFGNB other than } P \text {. aeruginosa } \\
\text { and Acinetobacter spp. }\end{array}$ & 2 & 5.4 \\
\hline 7) & Escherichia coli & 1 & 2.7 \\
\hline 8) & Serratia marcescens & 1 & 2.7 \\
\hline 9) & Moraxella catarrhalis & 1 & 2.7 \\
\hline \multicolumn{4}{|c|}{$\begin{array}{c}\text { Table 2: Bacterial Pathogens Isolated } \\
\text { During the Study Period }\end{array}$} \\
\hline
\end{tabular}

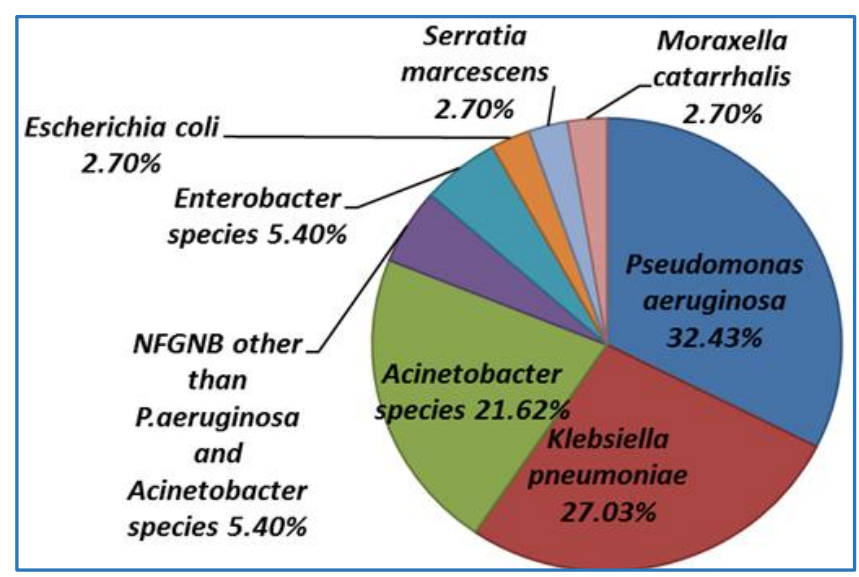

\begin{tabular}{|c|c|c|c|c|c|}
\hline \multirow{2}{*}{ Pathogen } & \multirow{2}{*}{ Total } & \multicolumn{2}{|c|}{ Ward } & \multicolumn{2}{|c|}{ ICU } \\
\cline { 3 - 6 } & & No. & $\%$ & No. & $\%$ \\
\hline $\begin{array}{c}\text { Pseudomonas } \\
\text { aeruginosa }\end{array}$ & 11 & 3 & 27.27 & 8 & 72.72 \\
\hline $\begin{array}{c}\text { Klebsiella } \\
\text { pneumoniae }\end{array}$ & 10 & 4 & 40 & 6 & 60 \\
\hline Acinetobacter spp. & 8 & - & - & 8 & 100 \\
\hline Enterobacter spp. & 2 & 1 & 50 & 1 & 50 \\
\hline $\begin{array}{c}\text { NFGNB other than } \\
\text { P.aeruginosa \& } \\
\text { Acinetobacter spp. }\end{array}$ & 2 & - & - & 2 & 100 \\
\hline $\begin{array}{c}\text { Escherichia coli } \\
\text { Serratia marcescens }\end{array}$ & 1 & - & - & 1 & 100 \\
\hline Moraxella catarrhalis & 1 & - & - & 1 & 100 \\
\hline \multicolumn{7}{|c|}{ Table 3: Distribution of the Bacterial } \\
Pathogens among Wards and ICUs \\
\hline
\end{tabular}

\begin{tabular}{|c|c|c|c|c|c|c|c|c|c|c|c|c|c|c|c|c|c|c|c|c|c|c|}
\hline \multirow{2}{*}{ Total } & \multicolumn{2}{|c|}{ AM } & \multicolumn{2}{|c|}{ PR } & \multicolumn{2}{|r|}{ CF } & \multicolumn{2}{|c|}{ PT } & \multicolumn{2}{|r|}{ GM } & \multicolumn{2}{|c|}{ AK } & \multicolumn{2}{|r|}{ RC } & \multicolumn{2}{|r|}{ TIGE } & \multicolumn{2}{|r|}{ COL } & \multicolumn{2}{|r|}{ MR } & \multicolumn{2}{|r|}{ CO-TRI } \\
\hline & \begin{tabular}{|l|} 
No. \\
\end{tabular} & $\%$ & No. & $\%$ & No. & \begin{tabular}{|l|}
$\%$ \\
\end{tabular} & No. & \begin{tabular}{|l|}
$\%$ \\
\end{tabular} & \begin{tabular}{|l|} 
No. \\
\end{tabular} & $\%$ & No. & \% & No. & \begin{tabular}{|l|}
$\%$ \\
\end{tabular} & No. & \begin{tabular}{|l|}
$\%$ \\
\end{tabular} & No. & $\%$ & \begin{tabular}{|l|} 
No. \\
\end{tabular} & \begin{tabular}{|l|}
$\%$ \\
\end{tabular} & No. & $\%$ \\
\hline 14 & 0 & \begin{tabular}{|l|}
0 \\
\end{tabular} & 0 & 0 & 6 & 42.86 & 6 & 42.86 & 5 & 35.71 & \begin{tabular}{|c|}
6 \\
\end{tabular} & 42.86 & 5 & 35.71 & \begin{tabular}{|l|l}
10 \\
\end{tabular} & \begin{tabular}{|l|}
71.43 \\
\end{tabular} & 13 & 92.86 & 10 & 71.43 & \begin{tabular}{|l|}
9 \\
\end{tabular} & 64.29 \\
\hline & & & & & & & able & 4:Ant & tibio & tic Sus & scepti & tibility & ?at & ern of & EnteI & erobact & teria & ceae & & & & \\
\hline
\end{tabular}

AM-Ampicillin, PR-Cephalexin, CF-Cefotaxime, PT-Piperacillin/Tazobactam, GM-Gentamicin, AK-Amikacin, RC-Ciprofloxacin, TIGETigecycline, COL-Colistin, MR-Meropenem, CO-TRI-Co-trimoxazole.

\begin{tabular}{|c|c|c|c|c|c|c|c|c|c|c|c|c|c|c|c|c|c|c|c|c|c|c|}
\hline \multirow{2}{*}{ Total } & \multicolumn{2}{|c|}{ AM } & \multicolumn{2}{|c|}{ PR } & \multicolumn{2}{|c|}{ CF } & \multicolumn{2}{|c|}{ PT } & \multicolumn{2}{|c|}{ GM } & \multicolumn{2}{|c|}{ AK } & \multicolumn{2}{|c|}{ RC } & \multicolumn{2}{|c|}{ TIGE } & \multicolumn{2}{|c|}{ COL } & \multicolumn{2}{|c|}{ MR } & \multicolumn{2}{|c|}{ CO-TRI } \\
\hline & No. & $\%$ & No. & $\%$ & No. & $\%$ & No. & $\%$ & No. & $\%$ & No. & $\%$ & No. & $\%$ & No. & $\%$ & No. & $\%$ & No. & $\%$ & No. & $\%$ \\
\hline 10 & 0 & 0 & 0 & 0 & 5 & 50 & 3 & 30 & 2 & 20 & 3 & 30 & 2 & 20 & 6 & 60 & 9 & 90 & 6 & 60 & 5 & 50 \\
\hline
\end{tabular}

\begin{tabular}{|c|c|c|c|c|c|c|c|c|c|c|c|c|c|c|c|c|c|c|c|c|c|}
\hline & \multirow{2}{*}{ Total } & \multicolumn{2}{|c|}{ PC } & \multicolumn{2}{|c|}{ GM } & \multicolumn{2}{|c|}{ AK } & \multicolumn{2}{|c|}{ PT } & \multicolumn{2}{|c|}{ RC } & \multicolumn{2}{|c|}{ COL } & \multicolumn{2}{|c|}{ MR } & \multicolumn{2}{|c|}{ IM } & \multicolumn{2}{|c|}{ FG } & \multicolumn{2}{|c|}{ CO-Tri } \\
\hline & & No. & $\%$ & No. & $\%$ & No. & $\%$ & No. & $\%$ & No. & $\%$ & No. & $\%$ & No. & $\%$ & No. & $\%$ & No. & $\%$ & \begin{tabular}{|l|} 
No. \\
\end{tabular} & $\%$ \\
\hline P. aeruginosa & 12 & 4 & 33.3 & 9 & 75 & 9 & 75 & 7 & 58.3 & 8 & 66.67 & 11 & 91.67 & 8 & 66.67 & 8 & 66.67 & 8 & 66.67 & NA & NA \\
\hline $\begin{array}{c}\text { Acinetobacter } \\
\text { spp. }\end{array}$ & 8 & 0 & 0 & 0 & 0 & 2 & 25 & 0 & 0 & 0 & 0 & 8 & 100 & 0 & 0 & 0 & 0 & 0 & 0 & 2 & 25 \\
\hline
\end{tabular}

PC-Piperacillin, GM-Gentamicin, AK-Amikacin, PT-Piperacillin/Tazobactam, RC-Ciprofloxacin, COL-Colistin, MR-Meropenem, IMImipenem, FG-Ceftazidime, CO-TRI-Co-trimoxazole. 


\begin{tabular}{|c|c|c|c|}
\hline Bacterial Isolate & Ward & ICU & Total \\
\hline K. pneumoniae & $4(100 \%)$ & $4(22.22 \%)$ & $8(36.36 \%)$ \\
\hline Acinetobacter species & 0 & $8(44.44 \%)$ & $8(36.36 \%)$ \\
\hline P. aeruginosa & 0 & $4(22.22 \%)$ & $4(18.18 \%)$ \\
\hline E. coli & 0 & $1(5.55 \%)$ & $1(4.5 \%)$ \\
\hline $\begin{array}{c}\text { NFGNB other than Acinetobacter } \\
\text { species and P. aeruginosa }\end{array}$ & 0 & $1(5.55 \%)$ & $1(4.5 \%)$ \\
\hline Total & $\mathbf{4}(\mathbf{1 0 0} \%)$ & $\mathbf{1 8 ~ ( 1 0 0 \% )}$ & $\mathbf{2 2 ( 1 0 0 \% )}$ \\
\hline Table 7: Distribution of Multidrug Resistant Respiratory Isolates in the Hospital \\
\hline
\end{tabular}

\section{DISCUSSION}

Many studies have reported male predominance in LRTIs.(12,16) In our study, 40 samples were from male patients $(74 \%)$ and 14 from female patients $(25.9 \%)$. In a study by Purti et al(2) $67.74 \%$ of the respiratory samples were from male patients and $32.26 \%$ from females. Shrestha et al(17) also reported a predominance of male patients in their study. Majority of accepted samples were from inpatients (94.4\%). This is in accordance with a study by Purti et al(2); $81.48 \%$ patients received at least one antibiotic prior to sample collection, which might interfere in the recovery of the pathogen if the organism is susceptible; 8 (14.81\%) samples did not yield any growth and $13(24.07 \%)$ samples were observed to have no significant growth/normal flora. In the study by Akter et al(16), 50 out of 105 sputum samples yielded no growth and they attributed this to viruses and previous treatment with antibiotics. Mishra et al(4) also highlighted the finding of culture negativity in their study, imparting this to the use of antibiotics; $57.4 \%$ of samples yielded predominant/significant growth of pathogens. The isolation rates are comparatively lower in other studies $-42.2 \%$ in a study by Purti et al(2), 31.2\% by Navaneeth et al(5) and 34.5\% by Jethwani et al(18), Navaneeth et al(5) report that $53.6 \%$ of samples in their study yielded normal pharyngeal flora and $15.1 \%$ did not yield any growth, whereas Jethwani et al(18) report that $65.5 \%$ of samples yielded no growth. In our work, polymicrobial growth was obtained in $6(11.11 \%)$ of samples. This rate can be compared with the finding of Mishra et al (9\%).(4) and Purti et al (13.37\%).(2)

Only Gram-negative bacteria were obtained in our study. Many other studies have obtained the similar results. $(4,7,17,18,19,20)$ The Gram-negative predominance in our study might partly be due to the unequal distribution of patients with community-acquired and hospital-acquired infections and also due to the spread of antibiotic resistance in hospital setting. The most common bacteria isolated in our study were Pseudomonas aeruginosa (32.43\%), Klebsiella pneumoniae (27.03\%) and Acinetobacter spp. (21.62\%), which is similar to many studies. $(5,8,9,12,17,19,21)$ The only possible reason for not recovering Gram-positive bacteria in our study could be the small number of outpatient samples (5.55\%). Purti et al(2), Ahmed et al(12), Ramana et al(19) and Egbe et al(22) have reported $K$. pneumoniae as the predominant isolate in their studies. Mishra et al(4), Shrestha et al(18) and Jafari et al(23) have $P$. aeruginosa as the most common bacterial isolate in their works.

Multiple drug resistance is a growing concern among respiratory pathogens, particularly those causing hospitalacquired infections. Of the 37 bacterial isolates, 22 (59.45\%) were MDR organisms; 15 out of the 22 MDR organisms were recovered from ICU patients. Faimow and Nahra.(15) state that the highest rates of MDR bacteria are found in the ICUs and selective pressures from intense antimicrobial exposure contributes to the emergence of MDR bacteria. De-escalation after receiving the culture and sensitivity reports is also not done in many ICUs, thus compounding the problem. The common MDR isolates in our study were $K$. pneumoniae (36.36\%) and Acinetobacter spp. (36.36\%). P. aeruginosa was comparatively more susceptible to antibiotics. Vishwanath et al(9) conducted a detailed study on MDR Gram negative bacilli causing lower respiratory infections. They had K. pneumoniae and Acinetobacter spp. as the commonest MDR isolates. Another salient issue is the growing predominance of MDR Acinetobacter species in our study (21.62\%). Acinetobacter species have emerged as a major cause of healthcareassociated infections, particularly hospital-acquired and ventilator-associated pneumonia.(24)

Colistin, Carbapenems, Tigecycline and Cotrimoxazole showed the highest in vitro efficacy against the coliform isolates in our study. $P$. aeruginosa also was highly susceptible to colistin followed by aminoglycosides. Colistin (Polymyxin E) was re-introduced in the context of multiple drug resistance among Gram-negative bacteria and lack of new antibiotics.(25) Tigecycline, a glycylcycline antibiotic, has in vitro activity against gram-positive and gram-negative bacteria including drug-resistant bacteria.(26) Carbapenems have been used as the last resort for infections caused by resistant Enterobacteriaceae. But Carbapenem-Resistant Enterobacteriaceae (CRE) have now been increasingly reported worldwide.(27) Kanj et $\mathrm{al}^{(28)}$ pointed that aminoglycosides, fluoroquinolones and cotrimoxazole must be used with caution in serious infections even when they are active in vitro.

In a study by Ahmed et al(12), K. pneumoniae exhibited a higher susceptibility to Imipenem followed by Piperacillin/tazobactam. $P$. aeruginosa displayed less resistance to fluoroquinolones. In our study, only $30 \%$ of $K$ pneumoniae strains were susceptible to Piperacillin/tazobactam and $60 \%$ susceptible to Carbapenem. High rates of resistance to cephalosporins was noticed in several studies.(12,20) Our observation about cephalosporins match with their findings. This might be due to the extensive use of $3^{\text {rd }}$ generation cephalosporins in hospitals. $P$. aeruginosa has $66.66 \%$ susceptibility to Meropenem and Imipenem each, whereas all the 8 Acinetobacter spp. were resistant to carbapenems. There are several antibioticresistance mechanisms working in $P$. aeruginosa and Acinetobacter spp. Moreover, high colonisation rates have been observed in the ICU setting, particularly in the respiratory tract. 


\section{LIMITATIONS}

A distinction between community-acquired and hospitalacquired infections could not be made. A complete data regarding the predisposing conditions could not be collected.

\section{CONCLUSION}

Antimicrobial resistance, initially associated with hospitalacquired infections, has now extended into the community also. In intensive care units and critical care units, antibiotic resistance rates are escalating to the point of complete resistance. With strategies such as 'antibiotic cycling' and 'antibiotic stewardship' gaining much importance now, it has become necessary to conserve the already available antibiotics. Hospitals should have an 'antibiotic policy' and facilities for proper monitoring of antibiotic usage along with effective infection control practices to curb the issue of antibiotic resistance worldwide. Moreover, determination of the type of bacterial pathogens and their antibiotic resistance trends aid in better patient management by helping the clinician in the judicious use of antibiotics.

\section{ACKNOWLEDGEMENTS}

We acknowledge the ICMR for granting the Short Term Studentship (STS) 2015 (Reference ID 2015-01395). We are thankful to the Dean and to the Management of MOSC Medical College for their encouragement and support. We also thank Dr. Anna Mathew, Research Co-ordinator, MOSC Medical College, for her constant support throughout the study. The contribution of Mr. Saravanan Velusamy (Biostatistician) in statistical analysis is also acknowledged.

\section{REFERENCES}

1. Murray CJL, Lopez AD. Mortality by cause for eight regions of the world: global burden of disease study. Lancet 1997;349(9061):1269-76.

2. Purti T, Kiran D. Lower respiratory tract infections: current aetiological trends and antibiogram. J Pharm Biomed Sci 2014;4(3):249-55.

3. Restrepo MI, Anzueto A. Antimicrobial treatment of community-acquired pneumonia. Pneumonia in the hospital setting. Clin Chest med 2005;26(1):65-73.

4. Mishra SK, Kattel HP, Acharya J, et al. Recent trend of bacterial aetiology of lower respiratory tract infections in a tertiary care centre of Nepal. Int J Infect Microbiol 2012;1(1):3-8.

5. Navaneeth BV, Belwadi MR. Antibiotic resistance among gram-negative bacteria of lower respiratory tract secretions in hospitalized patients. Indian J Chest Dis Allied Sci 2002;44(3):173-6.

6. Okesola AO, Ige OM. Trends in bacterial pathogens of lower respiratory tract infections. Indian J Chest Dis Allied Sci 2008;50(3):269-72.

7. Ozyilmaz E, Akan OA, Gulhan M, et al. Major bacteria of community-acquired respiratory tract infections in Turkey. Jpn J Infect Dis 2005;58(1):50-2.

8. Erling V, Jalil F, Hanson LA, et al. The impact of climate on the prevalence of respiratory tract infection in early childhood in Lahore, Pakistan. J Pub Health 1999;21(3):331-9.

9. Vishwanath S, Chawla K, Gopinathan A. Multidrug resistant gram negative bacilli in lower respiratory tract infections. Iran J Microbiol 2013;5(4):323-7.
10. Tedja R, Gordon S. Hospital-acquired, health careassociated, and ventilator-associated pneumonia. http://www.clevelandclinicmeded.com/medicalpubs/dis easemanagement/infectious disease/health-careassociated-pneumonia/, November 2013.

11. Guthrie R. Community acquired lower respiratory tract infections: aetiology and treatment. Chest 2001;120(6):2021-34.

12. Ahmed SM, Jakribettu RP, Meletath SK, et al. Lower respiratory tract infections (LRTIs): an insight into the prevalence and the antibiogram of the gram negative, respiratory, bacterial agents. Journal of clinical and Diagnostic Research 2013;7(2):253-6.

13. Bhatt $P$, Tandel K, Shete V, et al. Burden of extensively drug-resistant and pandrug-resistant gram-negative bacteria at a tertiary-care centre. New microbes and New infections 2015;8:166-70.

14. Winn W, Allen S, Janda W, et al. Introduction to microbiology-part I. Koneman's color atlas and textbook of diagnostic microbiology, Lippincott Williams \& Wilkins 2006; $6^{\text {th }}$ edn:1-66.

15. Fraimow H, Nahra R. Resistant gram-negative infections. Life-threatening infections: Part 2. Crit Care Clin 2013;29:895-921.

16. Akter S, Shamsuzzman SM, Jahan F. Community-acquired bacterial pneumonia: aetiology, laboratory detection and antibiotic susceptibility pattern. Malaysian J Pathol 2014;36(2):97-103.

17. Shrestha S, Acharya A, Nepal H, et al. Lower respiratory tract pathogens and their antimicrobial susceptibility pattern in a medical hospital of central Nepal. International Journal of Biomedical and Advance Research 2013;4(5):335-40.

18. Jethwani U, Shah N, Trivedi P. Antibiotic sensitivity pattern of gram negative bacilli isolated from the lower respiratory tract of ventilated patients in the intensive care unit. Indian Medical Gazette 2014;180-4.

19. Ramana KV, Kalaskar A, Rao M, et al. Aetiology and antimicrobial susceptibility patterns of lower respiratory tract infections (LRTIs) in a rural tertiary care teaching hospital at Karimnagar, South India. AmericanJournal of Infectious Diseases and Microbiology 2013;1(5):101-5.

20. Bajpai T, Shrivastava G, Bhatambare GS, et al. Microbiological profile of lower respiratory tract infections in neurological intensive care unit of a tertiary care centre from central India. Journal of Basicand Clinical Pharmacy 2013;4(3):51-5.

21. Kombade SP, Agrawal GN. Microbiological study of lower respiratory tract infections in ICU patients. Int J Curr Microbiol App Sci 2014;3(8):749-54.

22. Egbe CA, Ndiokwere C, Omoregie R. Microbiology of lower respiratory tract infections in Benin City, Nigeria. Malays J Med Sci 2011;18(2):27-31.

23. Jafari J, Ranjbar R, Haghi Ashtiani MT, et al. Prevalence and antimicrobial susceptibility of tracheal bacterial strains isolated from paediatric patients. Pakistan Journal of Biological Sciences 2009;12(5):455-8.

24. Hartzell JD, Kim AS, Kortepeter MG, et al. Acinetobacter pneumonia: a review. Med Gen Med 2007;9(3):4. 
25. Falagas ME, Kasiakou SK. Colistin: the revival of polymyxins for the management of multidrug-resistant gram-negative bacterial infections. Clinical infectious Diseases 2005;40(9):1333-41.

26. Dartois N, Cooper CA, Castaing N, et al. Tigecycline versus levofloxacin in hospitalized patients with communityacquired pneumonia: an analysis of risk factors. The Open Respir Med J 2013;7:13-20.
27. Morrill HJ, Pogue JM, Kaye KS, et al. Treatment options for carbapenem-resistant enterobacteriaceae infections. Open Forum Infectious Diseases 2015;2(2):1-139.

28. Kanj SS, Kanafani ZA. Current concepts in antimicrobial therapy against resistant gram-negative organisms: extended-spectrum $\beta$-lactamase-producing enterobacteriaceae, carbapenem-resistant entero-bacteriaceae, and multidrug-resistant pseudomonas aeruginosa. Mayo Clin Proc 2011;86(3):250-9. 